\title{
Research Article \\ Effect of Friction Coefficient on Relative Slippage of Fuel Cell Stack under Mechanical Impact Condition
}

\author{
Yongping Hou $\left(\mathbb{D},{ }^{1,2}\right.$ Leiqi Wang, ${ }^{1,2}$ Jianwen Zhang, ${ }^{3}$ and Dong Hao $\mathbb{D}^{4}$ \\ ${ }^{1}$ Lab of Clean Energy Automotive Engineering Center, Tongji University, Shanghai 201804, China \\ ${ }^{2}$ School of Automotive Studies, Tongji University, Shanghai 201804, China \\ ${ }^{3}$ Shanghai Motor Vehicle Inspection Certification \& Tech Innovation Center Co., Ltd., Shanghai 201805, China \\ ${ }^{4}$ China Automotive Technology and Research Center, Tianjin 300300, China
}

Correspondence should be addressed to Yongping Hou; yphou@tongji.edu.cn

Received 17 July 2017; Revised 6 December 2017; Accepted 18 December 2017; Published 1 February 2018

Academic Editor: Mohamed B. Trabia

Copyright (C) 2018 Yongping Hou et al. This is an open access article distributed under the Creative Commons Attribution License, which permits unrestricted use, distribution, and reproduction in any medium, provided the original work is properly cited.

\begin{abstract}
A simplified finite element model for large polymer electrolyte membrane fuel cell (PEMFC) stack consisting of ten cells is established in order to investigate the internal structure deformation. It is found that the interface slippage occurs when the bipolar plate (BP) and membrane electrode assembly (MEA) are subjected to vertical impact acceleration. Based on this three-dimensional model, the influence of the friction coefficient between BP and MEA on the relative slippage can be analyzed efficiently. The division layer of relative slippage is found and its vibration rule is discussed. It is observed that increasing the magnitude of impact vibration has most significant effect on the movement of the division layer, and the two variables are linearly related when impact acceleration is greater than $5 \mathrm{~g}$. This work provides important insight into the choice of the friction coefficient.
\end{abstract}

\section{Introduction}

Proton exchange membrane fuel cell is considered as an emerging technology which is convenient to transport. It can be used as device mobile power supply and daily power generation equipment $[1,2]$. As the main development object of vehicular fuel cell stack, it has become a long-term research focus and hotspot. Fuel cell stack (FCS) will inevitably be damaged by vibration and impact causing its performance degradation and durability deterioration under real road condition [2]; thus it is necessary to spread out researches in this area.

Numerical modelling and simulation calculation are significant methods to study the performance of fuel cell stack [1]. The advantage of simulation, compared with the traditional test, is that it can explore internal structure deformation of FCS under the premise of not destroying its integrity. A large number of literatures have shown that mechanical impact has an effect on the performance of fuel cell stack, but the internal structural distortion of FCS has not been analyzed in depth. Rouss et al. [3, 4] established a multiinput and multi-output fuel cell stack neural network model.
The comparison between the model-predicted data and the experimental data shows that the model has reliable precision and can be used to monitor the abnormity of FCS mechanical properties. Ahmed et al. [5] simplified the fuel cell stack to a $20 \mathrm{~cm} \times 20 \mathrm{~cm}$ composite plate structure to investigate the effect of material parameters such as Young's modulus or density on its natural frequency under random vibration condition. Rajalakshmi et al. [6] researched on the influence of the amplitude and frequency of mechanical vibration on the crack propagation rate based on a MEA numerical model. A single cell model is established for simulating by Deshpande et al. [7], the results show that, after one hour vibration of $10 \mathrm{~g}$, a slight movement of the seal causes the deterioration of airtightness and the displacement is considered to be linearly related to the acceleration amplitude; meanwhile the bolt torque is reduced by $20-25 \%$. Jiang [8] established a three-dimensional finite element model containing 100 single cells; it was found that the mechanical impact resulted in interlayer slippage and global deformation of FCS. Wu et al. [9] established a numerical model, and the results indicate that the initial assembling state change is caused by the impact load. Liu et al. [10] established an equivalent stiffness model 
TABLE 1: Size parameters of FCS components.

\begin{tabular}{lccc}
\hline Components & Thickness/mm & Length/mm & Width/mm \\
\hline MEA & 0.45 & 251 & 163 \\
Bipolar plate & 3 & 251 & 163 \\
Collecting plate & 1 & 251 & 163 \\
Insulating plate & 18 & 251 & 163 \\
Front plate & 20 & 271 & 220 \\
End plate & 25 & 271 & 220 \\
Rubber gasket & 8.5 & 251 & 163 \\
\hline
\end{tabular}

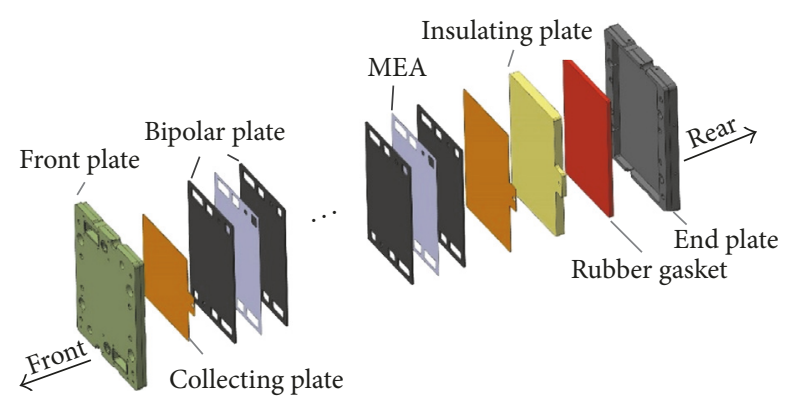

FIGURE 1: Schematic diagram of FCS components.

to analyze the structural stress which is produced by variable impact acceleration amplitude and clamping pressure. The conclusion is that the increase of longitudinal acceleration results in the narrowing down of the compression pressure range. Strengthening the longitudinal restraint stiffness makes encapsulated steel strips not easy to break and crack. The earliest numerical model is one-dimensional [11], which gradually develops into three-dimensional dynamic model. Finite element analysis is the general development trend of simulation.

Firstly, the internal structure deformation of FCS when subjected to vertical impact acceleration was investigated in this paper. Then, slippage of BP and MEA was analyzed by finite element simulation, and the anti-impact performance of FCS was evaluated by the index. The influence of various factors on the slippage was researched, particularly the friction coefficient between BP and MEA. It is proposed to choose a reasonable friction coefficient to optimize the mechanical structure for a better fuel cell stack performance.

\section{Model}

The polymer electrolyte membrane fuel cell (PEMFC) stack is composed of front plate, collecting plate, bipolar plate (BP), membrane electrode assembly (MEA), insulating plate, rubber gasket, and end plate, as shown in Figure 1. In this paper, the fuel cell stack is assembled by eight bolts. One membrane electrode assembly is sandwiched between two bipolar plates; for that reason the fuel cell stack generally contains $n$ layers MEA and $n+1$ layers BP. Single cell stack consists of one MEA and two BPs. First layer MEA refers to the MEA closest to the front plate, and the last layer MEA is closest to the end plate.

A three-dimensional finite element model of FCS was established using ABAQUS, as shown in Figure 2. The
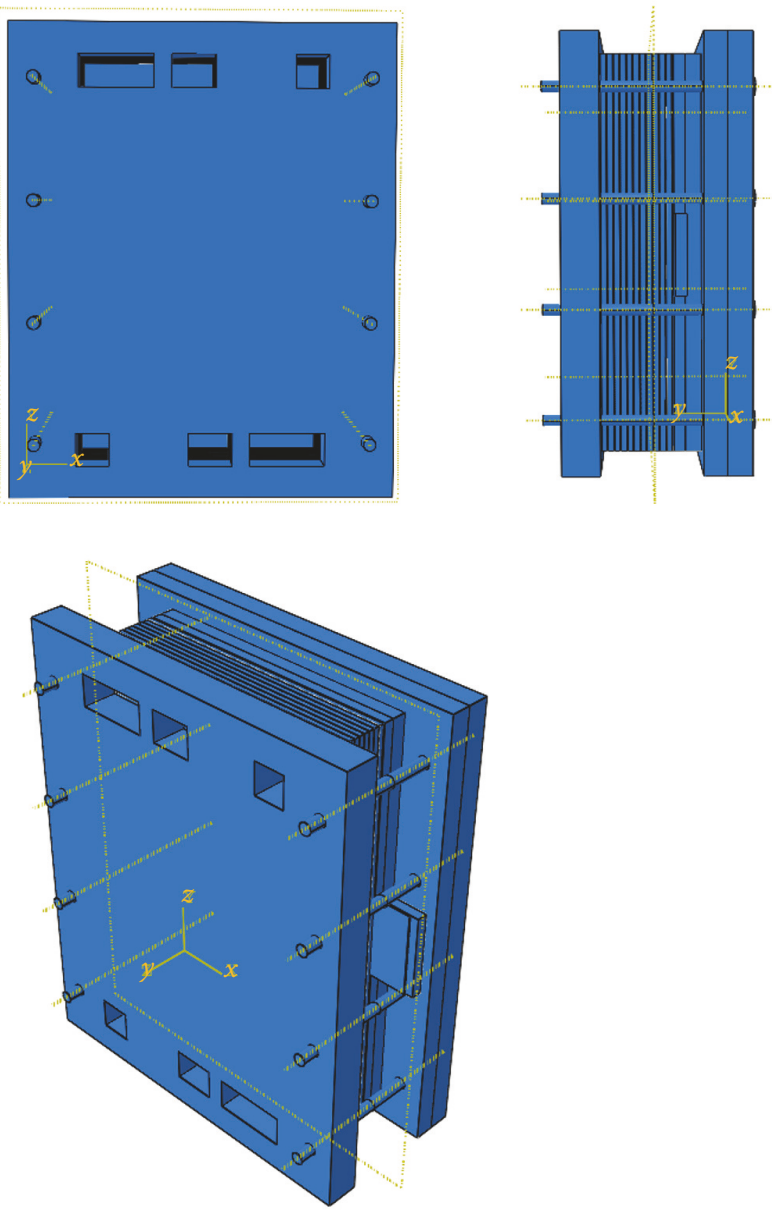

FIGURE 2: Simplified model of FCS.

dimension parameters of FCS components, shown in Table 1, were obtained by measuring an actual single cell stack, but the number of cells increased to ten. This model contains ten MEAs and eleven BPs. Some insignificant structures such as flow channel, chamfer, and thread were omitted to simplify the FCS model in terms of raising the computational efficiency.

\section{Parameter}

The finite element model uses C3D8R element (i.e., eightnode linear hexahedral element) for meshing to ensure a higher quality and accuracy of the grid. Total number of 
TABLE 2: Material properties of FCS components.

\begin{tabular}{|c|c|c|c|c|}
\hline Components & Material & Young's modulus/MPa & Poisson's ratio & Density $/ \mathrm{kg} \mathrm{m}^{-3}$ \\
\hline MEA & Carbon paper & 60 & 0.33 & 440 \\
\hline Bipolar plate & Graphite & 10000 & 0.25 & 2160 \\
\hline Seal & Silica gel & 5500 & 0.30 & 1700 \\
\hline Collecting plate & Copper & 100000 & 0.33 & 8940 \\
\hline Insulating plate & Phenolic resin & 13500 & 0.3 & 2200 \\
\hline End plate & Aluminium alloy & 69000 & 0.33 & 2800 \\
\hline Front plate & Epoxy resin & 22000 & 0.4 & 2200 \\
\hline Rubber gasket & Silica gel & 30 & 0.47 & 1150 \\
\hline
\end{tabular}

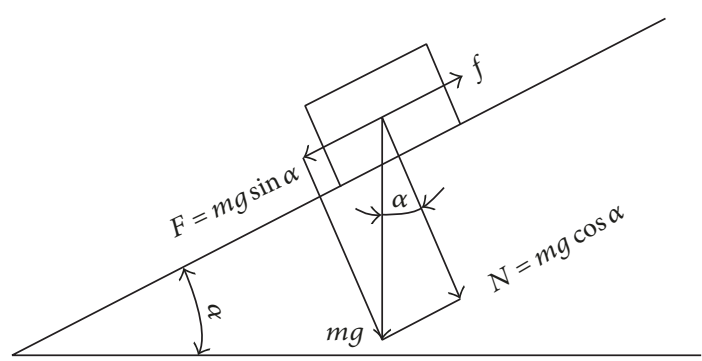

Figure 3: Schematic of measuring the friction coefficient.

element is 117,191 and total number of nodes is 180,541 . The approximate global size of seeds is five; the maximum deviation factor of the curvature control is 0.1. The minimum size is ten percent of global size. Material properties [12, 13] of each component including elastic modulus, Poisson's ratio, and density were defined, as shown in Table 2.

With the increase of clamping torque, interlayer clearance decreases to zero which means the adjacent components enter the surface contact state. In Interaction Module, surface-to-surface contact between two contacting surfaces was created. For example, three surfaces form two contact pairs that each refer to its own contact property definition. The contact property definition contains the friction definition. The option of contact property is tangential behavior, and the penalty contact method is used as the friction formulation.

The value of friction coefficient was obtained by rough measurement [14], as shown in Figure 3. Adjust the angle of the slope to the point where the component starts to slide itself and record the value of the angle. Repeat the process three times, and then take average. The tangent value of the angle is the friction coefficient, as shown in Table 3 . The value of 0.76 is specified for the friction coefficient between BP and MEA.

Create load and boundary condition in Load Module. Load category is mechanical; load type is bolt load. A clamping torque of $5 \mathrm{Nm}$ is exerted on eight bolts, respectively. Three analysis steps were created, including initial step, static step, and dynamic step. In the initial step, boundary condition type is displacement. The displacement value will be maintained in subsequent steps. Model was constrained to move only in $X$ and $Z$ direction. In the dynamic step, boundary condition type is acceleration and varies with given
TABle 3: Friction coefficient for each contact pair.

\begin{tabular}{lcc}
\hline Contact pair & Angle $^{\circ}$ & Friction coefficient $^{\circ}$ \\
\hline Front plate-BP & 18.83 & 0.34 \\
MEA-BP & 37.17 & 0.76 \\
BP-collecting plate & 14.33 & 0.26 \\
Collecting plate-insulating plate & 15.33 & 0.27 \\
Insulating plate-rubber gasket & 30.33 & 0.59 \\
\hline
\end{tabular}

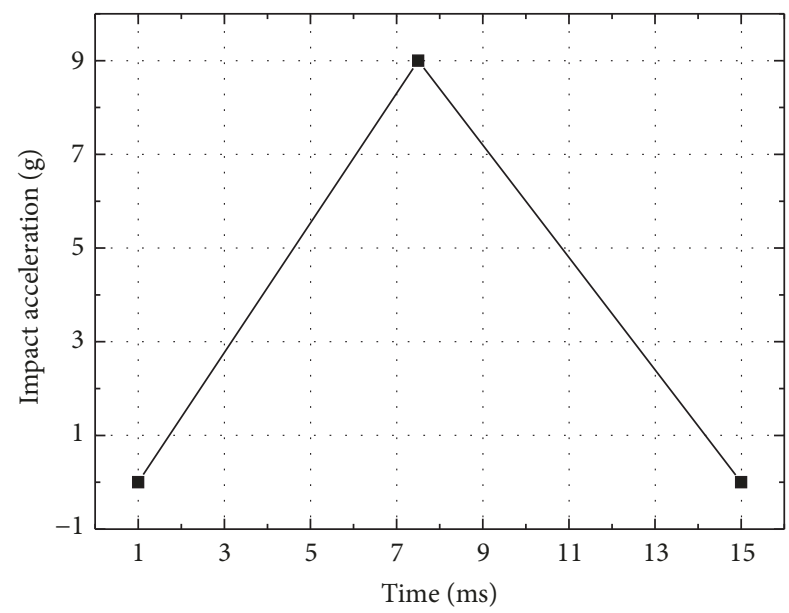

FIgURE 4: The impact impulse curve of $9 \mathrm{~g}$ impact acceleration.

amplitude. Both front and end plate were applied by a $9 \mathrm{~g}$ vertical impact acceleration, obtained by vehicular fuel cell stack vibration and durability test under strengthening road condition. Its amplitude is a triangular wave which lasted for $15 \mathrm{~ms}$, as shown in Figure 4.

In the vibration and durability test, the maximum acceleration in $X, Y$, and $Z$ direction is $6 \mathrm{~g}, 8 \mathrm{~g}$, and $9 \mathrm{~g}$, respectively. The maximum acceleration is equal to the measured acceleration multiplied by parts safety factor and then rounded to the nearest whole number. Vertical direction (i.e., $Z$ direction) obviously suffered the largest impact acceleration, which might make a major contribution to mechanical performance degradation of vehicular fuel cell stack. To avoid the multidirectional coupling effect, this paper studies the displacement response of FCS when applied to the sole vertical impact. Job was submitted using ABAQUS/Implicit. 


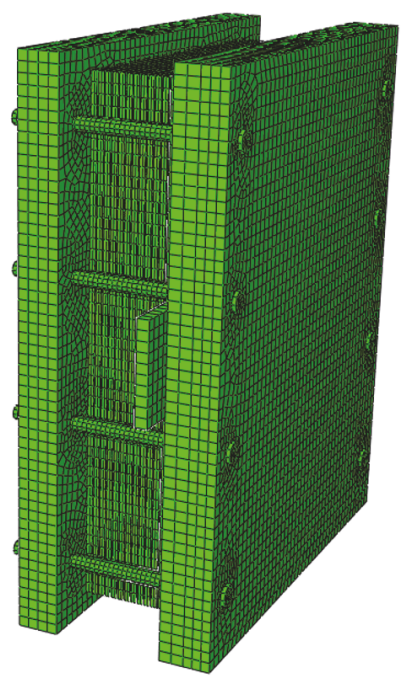

FIGURE 5: The displacement response of FCS under a $9 \mathrm{~g}$ impact acceleration.

\section{Results and Discussion}

4.1. Relative Slippage of $B P$ and $M E A$. The displacement response of FCS was obtained in ABAQUS Visualization Module. The maximum absolute displacement appears on the front plate; the value is $5.0625 \mathrm{~mm}$. It was observed that $9 \mathrm{~g}$ impact acceleration can lead to the slight slippage vertically but does not show any significant mechanical damage or destruction, shown in Figure 5.

The vertical slippage includes absolute and relative slippage. The absolute slippage is defined as the slippage of each component relative to the initial position. And the relative slippage of each component is equivalent to its absolute slippage minus the absolute slippage of front plate. So, the absolute slippage of each bipolar plate can be calculated using

$$
\Delta x_{b i}=\left(x_{b i}-x_{q}\right) \times 10^{3} \quad(i=1,2, \ldots, 11),
$$

where $\Delta x_{b i}$ is the relative slippage of the $i$ th bipolar plate $(\mu \mathrm{m}) ; x_{b i}$ is the absolute slippage of the $i$ th bipolar plate $(\mathrm{mm})$; $x_{q}$ is absolute slippage of the front plate $(\mathrm{mm})$.

Analogously, the relative slippage of MEA can be calculated using

$$
\Delta x_{m i}=\left(x_{m i}-x_{q}\right) \times 10^{3} \quad(i=1,2, \ldots, 10),
$$

where $\Delta x_{m i}$ is the relative slippage of the $i$ th $\operatorname{MEA}(\mu \mathrm{m}) ; x_{m i}$ is the absolute slippage of the $i$ th MEA $(\mathrm{mm}) ; x_{q}$ is absolute slippage of the front plate $(\mathrm{mm})$.

The analysis showed that eleven BPs and ten MEAs slip infinitesimally along the vertical direction. In order to reflect variation tendency directly and make it convenient to compare, the following research is directed at the relative slippage of BP and MEA. Figure 6 shows the relative slippage variation curve of $\mathrm{BP}$ and MEA; its abscissa represents sequence number of plate. It was found that the relative slippage of eleven BPs is very small. The relative slippage increases nonlinearly as the number of plate increases; the

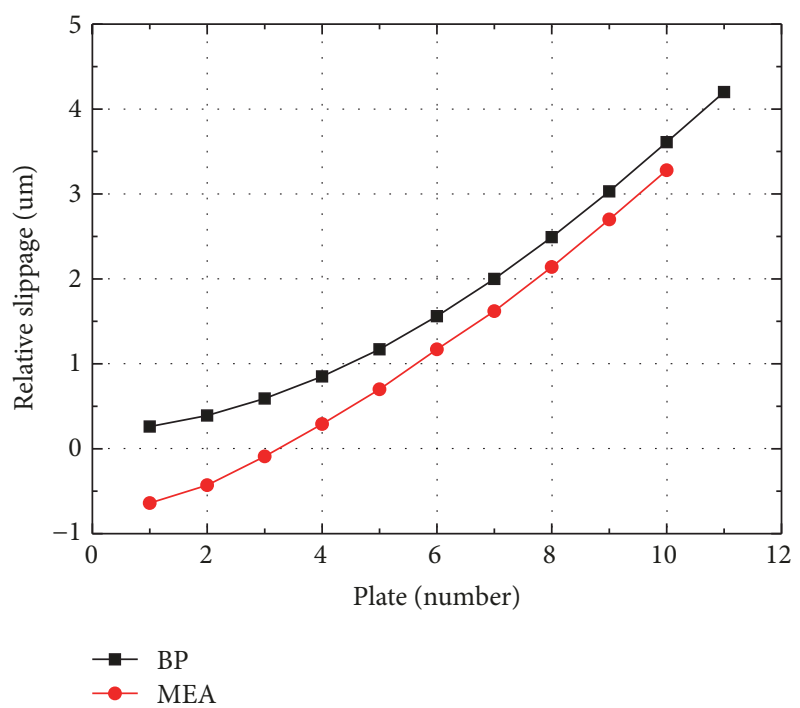

FIGURE 6: The relative slippage of BP and MEA under a $9 \mathrm{~g}$ impact acceleration.

maximum relative slippage of $\mathrm{BP}$ is $4.2 \mu \mathrm{m}$, which occurs in the eleventh layer BP; the variation law of MEA is similar to $\mathrm{BP}$; the maximum relative slippage of MEA is $3.3 \mu \mathrm{m}$, which occurs in the tenth layer MEA. The results indicate that the interlayer sliding appears between BP and MEA under a $9 \mathrm{~g}$ vertical impact acceleration. The relative slippage is used as a criterion to evaluate anti-impact performance of FCS. The smaller the relative slippage, the better the anti-impact performance.

4.2. Effect of Friction Coefficient on Relative Slippage. The relative displacement of single cell is affected by the interlayer friction coefficient, the package pressure, and the impact load [8]. Impact load is uncontrollable and depends on the external circumstances. Packing pressure also belongs to the external influencing factors. Interlayer friction coefficient has a critical implication on the relative slippage, and both BP and MEA are key components of fuel cell stack, so this paper mainly explores the influence of the friction coefficient between BP and MEA on the relative slippage.

The friction coefficient between BP and MEA is 0.76 as mentioned previously. Materials widely used in BP and MEA are graphite and carbon paper. The values of friction coefficient were defined from 0.2 to 0.8 with an interval of 0.2 . The influence of different friction coefficient on the relative slippage was well studied by simulation. It was observed that the relative slippage curve of $\mathrm{BP}$ has a point of intersection and it was named "division point," as well as the MEA relative slippage curve, as shown in Figure 7.

The horizontal axis of the division point refers to the ninth-layer BP and eighth-layer MEA. Although the friction coefficient is different, the relative slippage value of the ninth layer $\mathrm{BP}$ is almost the same. It indicates that the relative slippage of ninth-layer BP is not affected by the friction coefficient. The ninth-layer BP was named as "division layer of BP." Analogously, eighth-layer MEA is the division layer of MEA. The division layers of BP and MEA are collectively named "the division layer of relative slippage." The division 

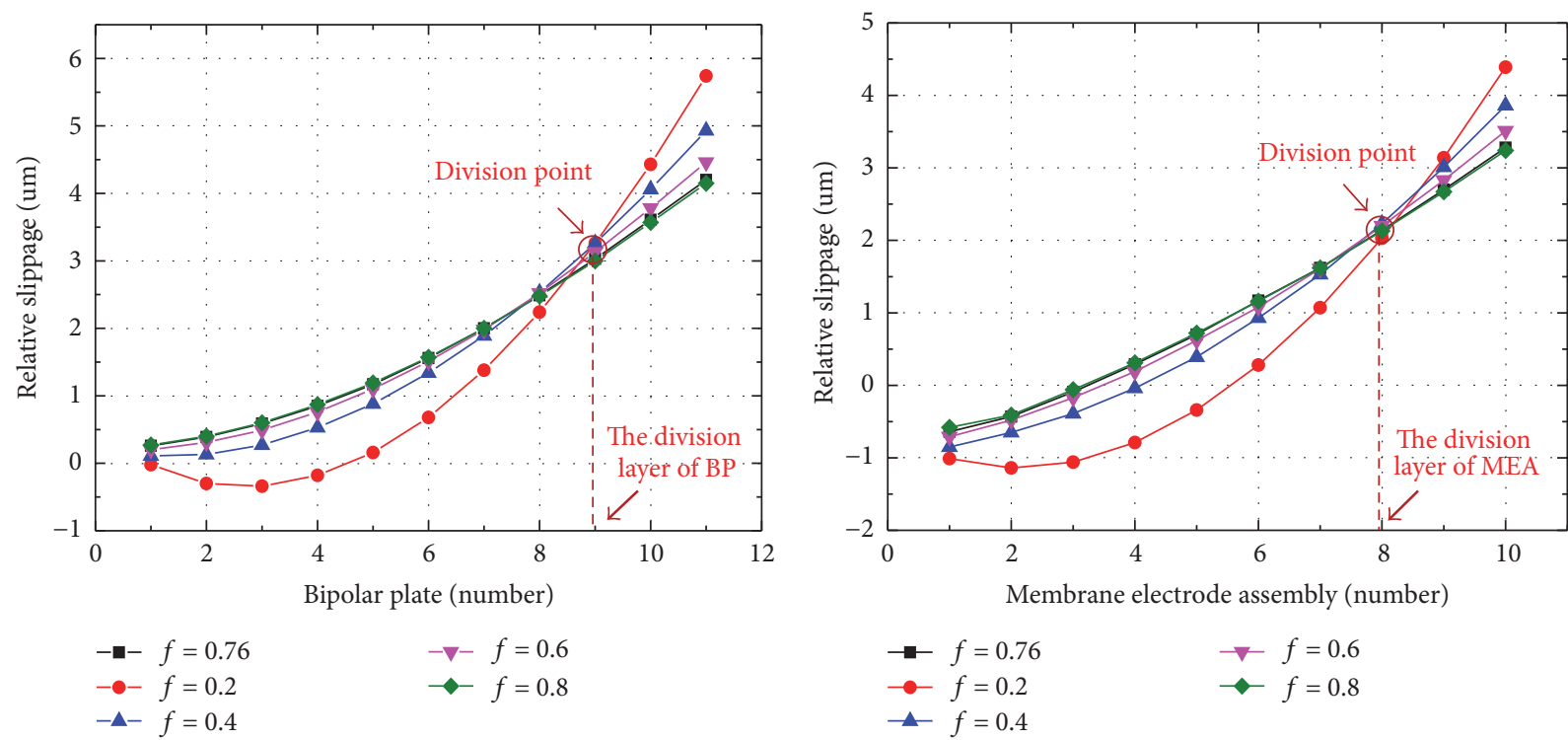

FIgURE 7: The division layer of BP or MEA versus friction coefficient under $9 \mathrm{~g}$ impact acceleration.
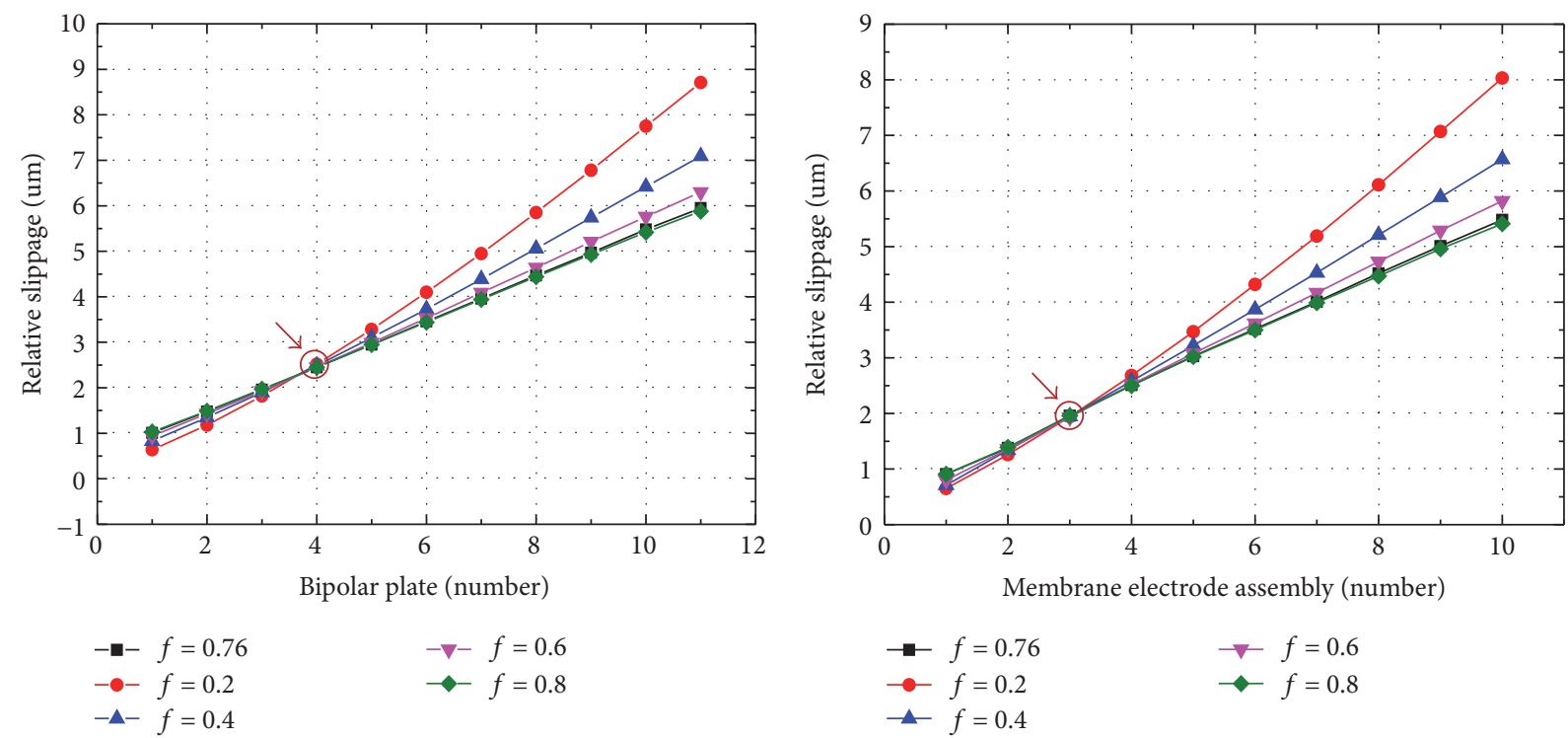

FIgURE 8: The division layer of relative slippage under $3 \mathrm{~g}$ impact acceleration.

layer of relative slippage is defined as the layer where the relative slippage is constant and does not vary with the friction coefficient. The BP or MEA is located in front of the division layer slip smaller along the vertical direction than the one behind the division layer. In front of the division layer, the relative slippage is proportional to the friction coefficient between BP and MEA, and, with the decrease of friction coefficient, the smaller the relative slippage, the better the anti-impact performance of FCS. However, the relative slippage of the plate behind the division layer is inversely proportional to the friction coefficient; the smaller the friction coefficient, the greater the relative slippage, the worse its anti-impact performance. It is suggested that a smaller friction coefficient between BP and MEA should be selected in front of the division layer of relative slippage, and a larger friction coefficient should be selected behind.

4.3. Division Layer of Relative Slippage and Its Changing Rule. According to the vehicular fuel cell stack vibration and durability test, the minimum acceleration of fuel cell stack is $3 \mathrm{~g}$, and it enlarges to $9 \mathrm{~g}$ approximately after multiplying by the safety factor. The acceleration amplitudes of $3 \mathrm{~g}, 4 \mathrm{~g}$, $5 \mathrm{~g}$, and $7 \mathrm{~g}$ were simulated separately. The simulation results show that the division layer of relative slippage is affected by the impact acceleration magnitude. The relative slippage curve has rough approximations of the change curve under $9 \mathrm{~g}$ impact acceleration. The division layer of relative slippage also occurred and can be observed intuitively under each impact acceleration, as shown in Figures 8, 9, 10, and 11. It 

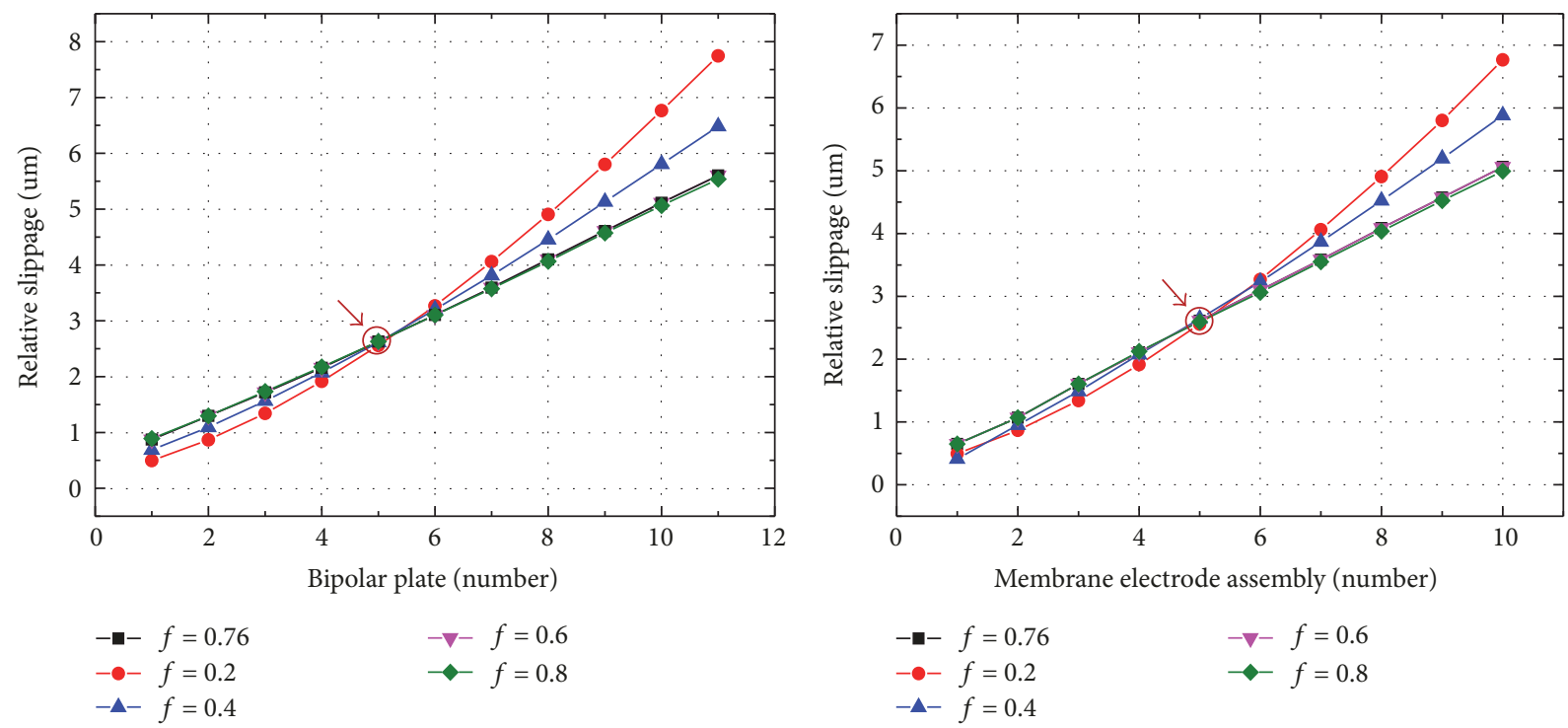

FIGURE 9: The division layer of relative slippage under $4 \mathrm{~g}$ impact acceleration.
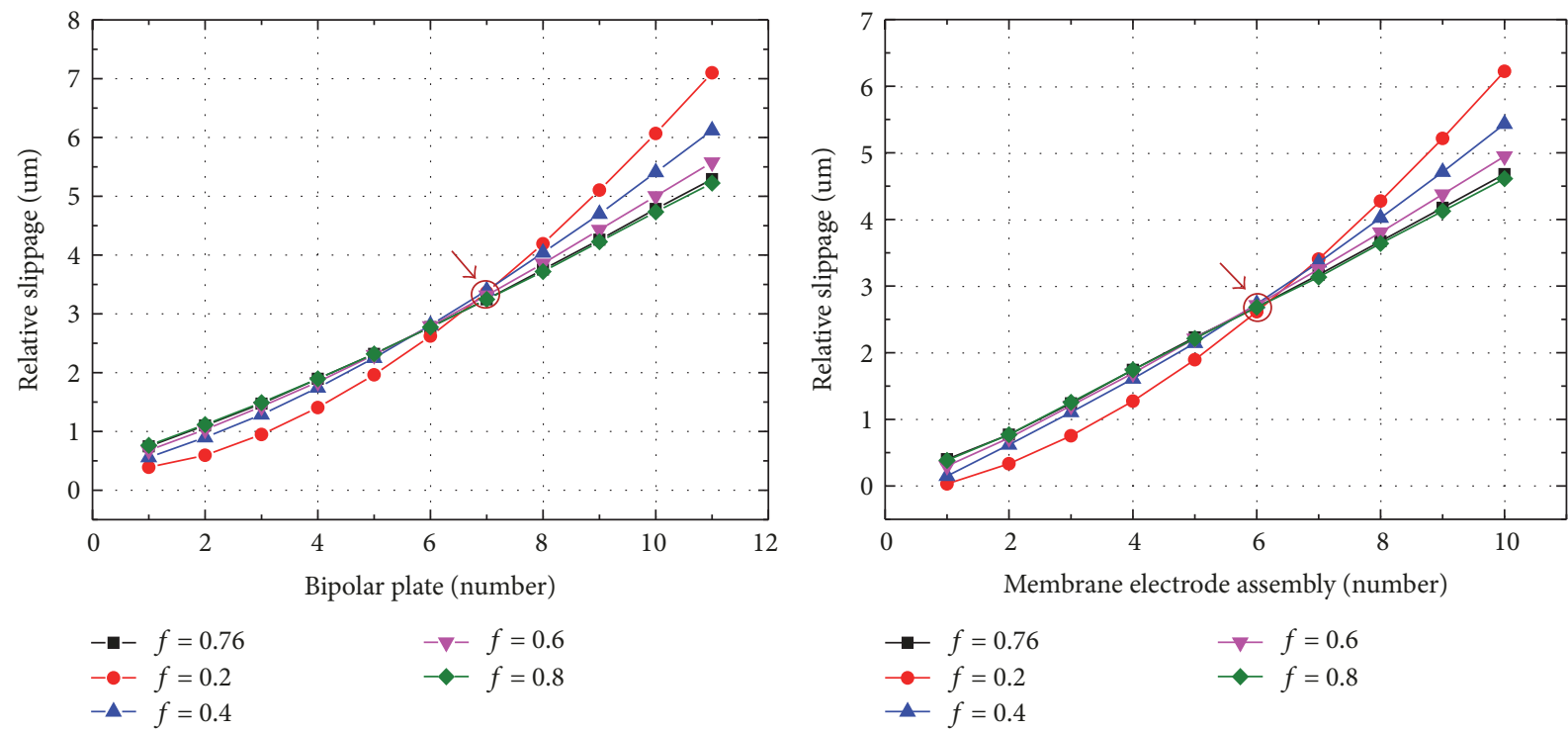

FIGURE 10: The division layer of relative slippage under $5 \mathrm{~g}$ impact acceleration.

is obvious the division layer of relative slippage is not fixed and moves with the impact acceleration magnitude.

The division layers of relative slippage of $3 \mathrm{~g}, 4 \mathrm{~g}, 5 \mathrm{~g}, 7 \mathrm{~g}$, and $9 \mathrm{~g}$ impact acceleration were synthesized in one graph, shown in Figure 12. It was found that the division layer of relative slippage is shifted with the increase of the impact acceleration, and the division layer of MEA is always in front of the division layer of BP; for example, the division layer of $\mathrm{BP}$ is the seventh-layer BP; then, the division layer of MEA is the sixth-layer MEA. It represents that the division layer happens to be the contact surface of the two layers (one is the division layer of BP; the other is the division of MEA).

The change curve is presented as two segments with $5 \mathrm{~g}$ acceleration as the dividing point. The division layer is closer to the end plate with load increasing. When impact acceleration is greater than $3 \mathrm{~g}$ and less than $5 \mathrm{~g}$, larger slope of the variation curve indicates fast moving speed, and the nonlinear characteristic is presented. When impact acceleration is greater than $5 \mathrm{~g}$, the slope of the variation curve is significantly reduced and the linear correlation is shown. It indicates that the division layer of relative slippage moves slower. The division layer of relative slippage is linearly related to the amplitude of impact acceleration.

\section{Summary/Conclusions}

The following conclusions can be obtained through the analysis of this work: 

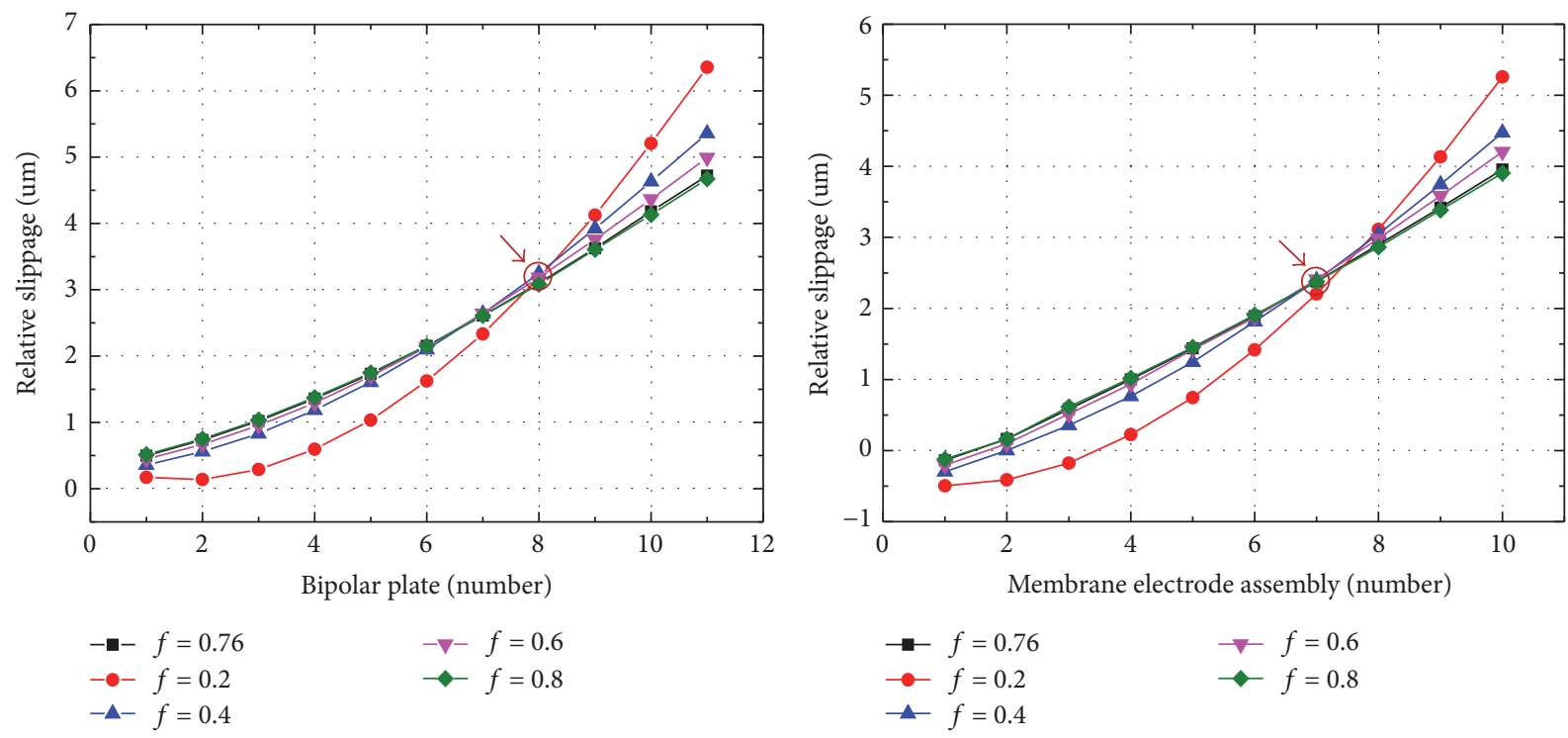

FIGURE 11: The division layer of relative slippage under $7 \mathrm{~g}$ impact acceleration.

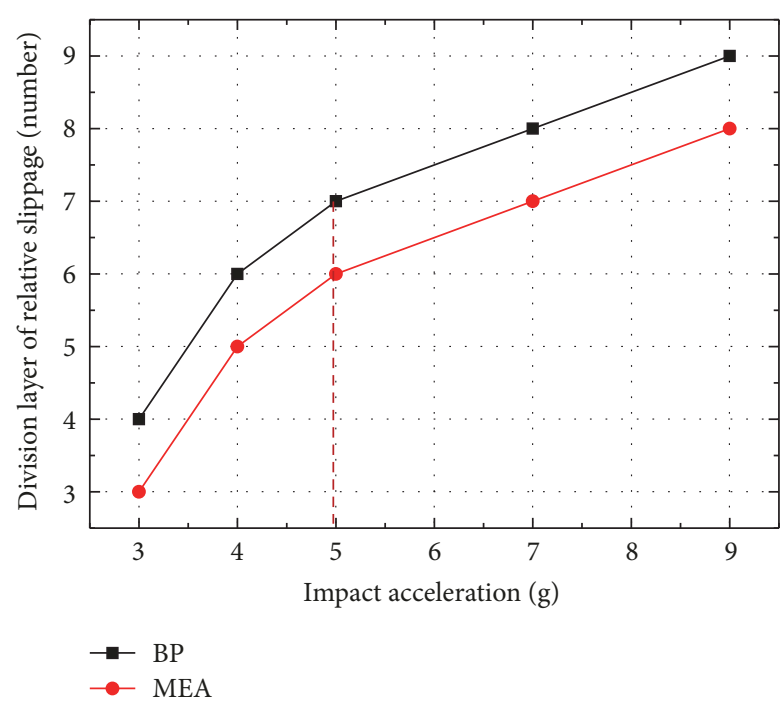

FIGURE 12: Change rule of the division layer of relative slippage.

(1) Slight interface relative slippage occurs between MEA and $\mathrm{BP}$ when subjected to the vertical impact acceleration.

(2) There is a division layer of relative slippage where the friction coefficient between BP and MEA has no influence on the relative slippage. The relative slippage is proportional to the friction coefficient in front of the division layer and vice versa.

(3) The division layer of relative slippage moves backward with the increase of the impact acceleration. When the impact acceleration is larger than $5 \mathrm{~g}$, the moving speed slows down significantly. The division layer of relative slippage is linearly correlated with the impact acceleration amplitude.

\section{Conflicts of Interest}

The authors declare that there are no conflicts of interest regarding the publication of this paper.

\section{Acknowledgments}

The research was financially supported under the grants of the National Nature Science Foundation of China, Project no. 51275357, and Shanghai Science and Technology Commission, Project no. 16DZ1204201.

\section{References}

[1] C. Siegel, "Review of computational heat and mass transfer modeling in polymer-electrolyte-membrane (PEM) fuel cells," Energy, vol. 33, no. 9, pp. 1331-1352, 2008.

[2] B. L. Yi, "Fuel cell: fundamental, technology and prospect," Chinese Battery Industry, pp. 160-329, 2003.

[3] V. Rouss, P. Lesage, S. Bégot et al., "Mechanical behaviour of a fuel cell stack under vibrating conditions linked to aircraft applications part I: Experimental," International Journal of Hydrogen Energy, vol. 33, no. 22, pp. 6755-6765, 2008.

[4] V. Rouss, D. Candusso, and W. Charon, "Mechanical behaviour of a fuel cell stack under vibrating conditions linked to aircraft applications part II: Three-dimensional modelling," International Journal of Hydrogen Energy, vol. 33, no. 21, pp. 6281-6288, 2008.

[5] H. E. U. Ahmed, R. Banan, J. W. Zu, and A. Bazylak, "Free vibration analysis of a polymer electrolyte membrane fuel cell," Journal of Power Sources, vol. 196, no. 13, pp. 5520-5525, 2011.

[6] N. Rajalakshmi, S. Pandian, and K. S. Dhathathreyan, "Vibration tests on a PEM fuel cell stack usable in transportation application," International Journal of Hydrogen Energy, vol. 34, no. 9, pp. 3833-3837, 2009.

[7] J. Deshpande, T. Dey, and P. C. Ghosh, "Effect of vibrations on performance of polymer electrolyte membrane fuel cells," 
in Proceedings of the 4th International Conference on Advances in Energy Research, ICAER 2013, pp. 756-762, India, December 2013.

[8] H.-N. Jiang, Optimization Design And Mechanical Respond to Dynamic Impact in Proton Exchange Membrane Fuel Cells, Dalian University of Technology, 2013.

[9] C.-W. Wu, B. Liu, M.-Y. Wei, and W. Zhang, "Mechanical response of a large fuel cell stack to impact: A numerical analysis," Fuel Cells, vol. 15, no. 2, pp. 344-351, 2015.

[10] B. Liu, M. Y. Wei, W. Zhang, and C. W. Wu, "Effect of impact acceleration on clamping force design of fuel cell stack," Journal of Power Sources, vol. 303, pp. 118-125, 2016.

[11] H. Zhang, B. Yi, M. Hou, and F.-T. Qiao, "Materials for bipolar plates in proton-exchange membrane fuel cells and their preparation," Chinese Journal of Power Source, vol. 27, no. 2, pp. 129-133, 2003.

[12] C.-Y. Wen, Y.-S. Lin, and C.-H. Lu, "Experimental study of clamping effects on the performances of a single proton exchange membrane fuel cell and a 10-cell stack," Journal of Power Sources, vol. 192, no. 2, pp. 475-485, 2009.

[13] J. Ge, A. Higier, and H. Liu, "Effect of gas diffusion layer compression on PEM fuel cell performance," Journal of Power Sources, vol. 159, no. 2, pp. 922-927, 2006.

[14] H.-S. Zhen and H. Liu, "Test method for Coefficient Static Friction by Use of the Inclined Plane Method Accurately," Modern Manufacturing Technology and Equipment, vol. 3, pp. 73-74, 2009. 


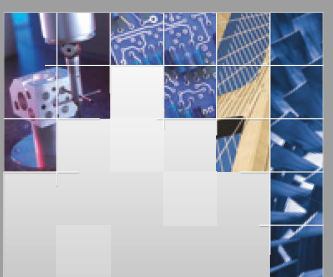

\section{Enfincering}
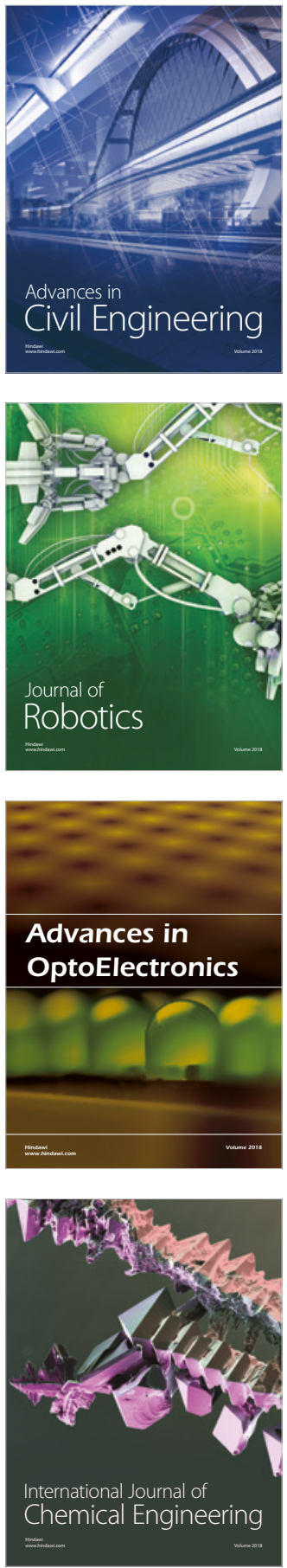

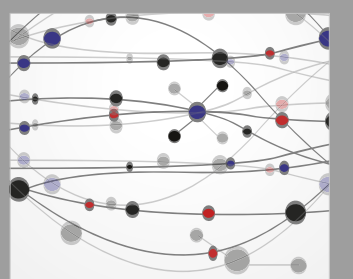

\section{Rotating \\ Machinery}

The Scientific World Journal

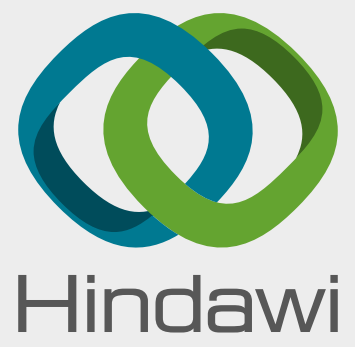

Submit your manuscripts at

www.hindawi.com
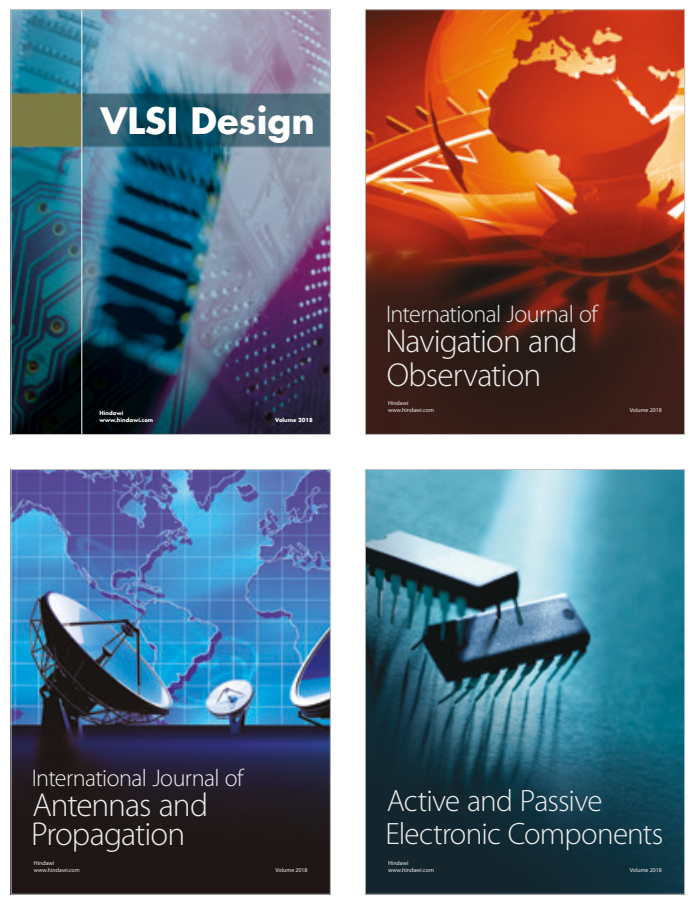
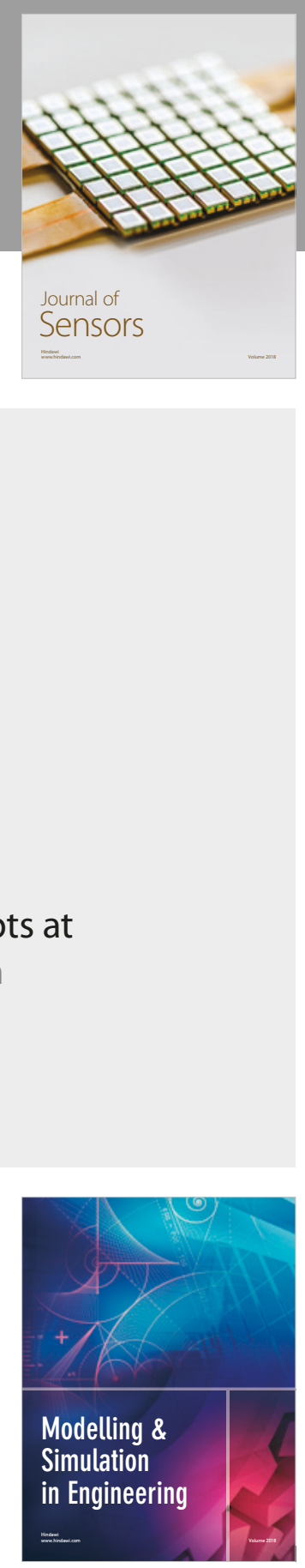

\section{Advances \\ Multimedia}
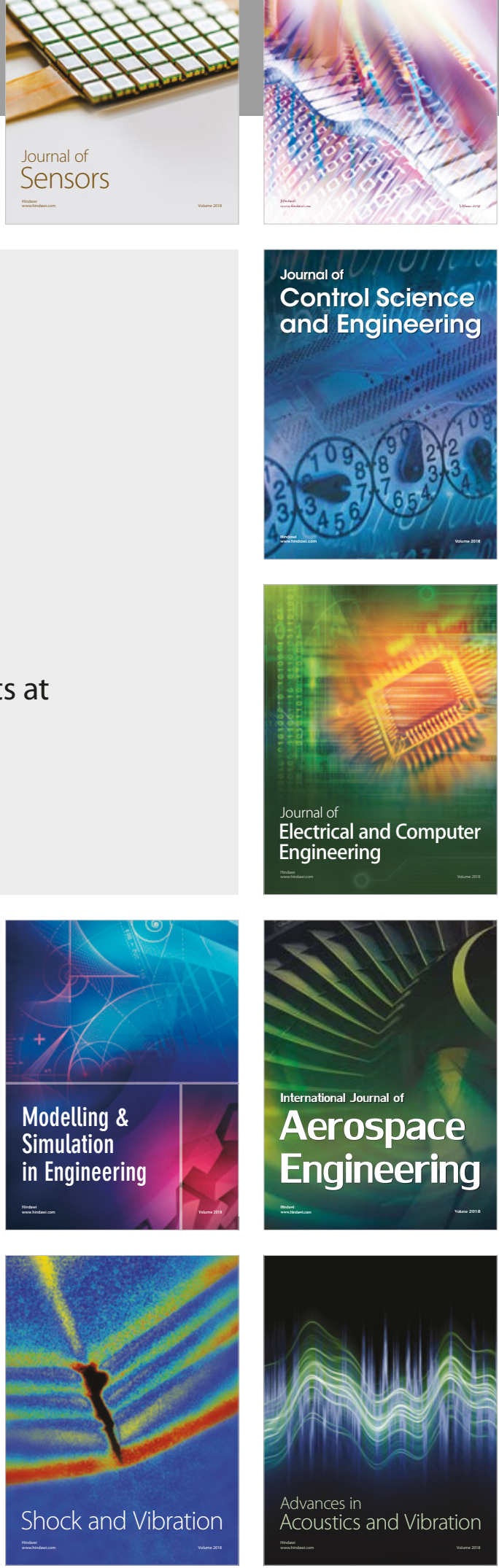